\title{
Modern techniques of teaching bovine rectal palpation: opportunities, benefits and disadvantages of new educational devices
}

\author{
JĘDRZEJ M. JAŚKOWSKI, JAROSŁAW SOBOLEWSKI, MARIA WIECZORKIEWICZ, \\ MAREK GEHRKE, MAGDALENA HERUDZIŃSKA
}

Institute of Veterinary Medicine, Faculty of Biological and Veterinary Sciences, Nicolaus Copernicus University, ul. Gagarina 7, 87-100 Toruń, Poland

\section{Jaśkowski J. M., Sobolewski J., Wieczorkiewicz M., Gehrke M., Herudzińska M. Modern techniques of teaching bovine rectal palpation: opportunities, benefits and disadvantages of new educational devices}

\section{Summary}

Rectal palpation has been an integral part of a clinical examination of large animals. This seemingly easy technique can pose certain difficulties for veterinarians and therefore requires considerable training. The rectal examination course included in the traditional program of veterinary studies is mainly based on practical classes with live animals. However, there is a common belief that the use of live patients is burdened with certain disadvantages in the form of a lack of control over the student's actions. What is more, a rectal palpation can have a negative effect on the animal organism. Following the increased focus on animal welfare in society and taking into account both ethical and medical concerns, a number of alternative teaching devices have appeared on the market in order to replace or significantly reduce the participation of live animals in the didactic process. Breed'n Betsy - one of the first simulators - is used to teach the diagnosis of the oestrus cycle and pregnancy phase as well as the artificial insemination or the embryo transfer. The appliance was soon followed by more technically advanced didactic equipment. Simulators, such as Haptic Cow, use virtual reality and haptic technology. The computer-generated, virtual objects representing the cow's anatomical structure are displayed on the screen. This technique enables the tutor to follow student's movements "inside the cow" and provide them with immediate instructions. Numerous studies indicate that the use of simulators, integrated with the traditional teaching techniques, brings highly satisfactory results.

Keywords: rectal examination, virtual simulators, cows

The rapid development of veterinary science, social, as well as legal changes require an introduction of certain adaptation techniques. The profession of a veterinarian is evolving in order to keep up with the pace of novelties in clinical practice, scientific discoveries and educational strategy, while at the same time ensuring the compliance with the public mandate in terms of educating professionally competent doctors (33). At present, academic teachers are obliged to prepare students for starting veterinary practice in the course of a 4-year intensive program of professional education. It requires ensuring competent training, conducted on dead, sedated or conscious animals. The aim of the training should be gaining proficiency in veterinary knowledge in the desired areas, as well as acquiring relevant practical skills. Undoubtedly, experience in working with animals is essential for preparing students for the profession which is inseparably related to them. The use of animals for didactic purposes is also conditioned by a growing number of rigorous legal regulations and is meticulously monitored by animal protection groups, becoming a subject of a wide debate. It thus comes as no surprise that partly due to those reasons the use of animals for professional education purposes has significantly declined (18). Among major challenges related to reaching the required educational outcome there are limitations resulting from factors such as animals' wellbeing which affect the availability of real patients for the purpose of training (33). As a result, during the last few decades new teaching methods have appeared, which allow for less consumption-related use of animals in this respect. They are mainly based on experiments from the field of medicine, making a wide use of simulation methods in education. The use of simulators ensures 
safe and more ethical alternative methods of teaching the basic clinical processes. The change is progressing quickly and on a large scale also in the field of veterinary medicine, proving that such an approach may serve as a model for further development in the veterinary educational environment $(31,33)$. Plentiful evidence suggests that by introducing well-designed teaching methods which make use of alternative methods one can attain a compromise between the well-understood educational mission and well-being of animals, at the same time minimizing the financial and time-related burdens related to unjustified use of animals (22).

\section{Per rectum examination of cows in field conditions}

At present, rectal palpation is the cheapest and the most convenient method which is of crucial importance in the proper management of reproduction, quick and correct early pregnancy diagnosis, as well as diagnosing problems related to cycle or fertility distortions $(15,19,20,27,32)$. Conducted in real-life conditions, it has been, and still is, a necessary element of clinical education. A number of studies indicate that good training of veterinary doctors in per rectum palpation may translate into increased fertility of cows, and has tangible economic significance (32). Despite that, there is a scarce body of research concerning the proper method of training on live animals (11). In one of the experiments, 10 students who had been intensely training to perform the procedure on live cows for a whole year were evaluated by means of practical tests performed in three periods (September, January and March). The results were analyzed with reference to the aforementioned points in time and the category of experience acquired during training on a particular number of animals (0-50, $50-100,100-150,150-200$ and more than 200 cows). The results improved over time, and were significantly better in categories 3, 4 and 5, than in category 1. Although all the students who had examined between 100 and 200 cows had no difficulty with locating the cervix, uterus and ovaries, they had problems with interpreting the changes diagnosed within the examined organs, which suggests that even examining 200 cows is not enough to reach the full level of specialist skills (9). Field observations indicate that diagnoses made by veterinarians with vast experience quite possibly - in relation to a selected ovarian structure - carries a high risk of error $(17,19$, $25)$. Numerous studies have presented ways to improve the accuracy of evaluating ovarian structures $(8,17$, 19). Factors of certain influence on the maximization of results seem to be motivation and students' previous expectations. The aim of the experiments was to define the level of skills and competences acquired by students of veterinary medicine in the course of training in rectal palpation of non-pregnant cows. The surveys were addressed to students classified into two groups: buiatrically motivated (SBM; $=22$ ) and non-motivated (SNBM; $n=28$ ). After completing the training within the reproduction module, representatives of the SMB groups demonstrated fewer difficulties with palpation examinations than those classified as SNBM. Higher skills were observed in the case of recognizing the left and right corner of the uterus $(71.4 \%$ vs $52.1 \%)$, identifying the right $(69.6 \%$ vs $52.1 \%)$ and left $(63.6 \%$ vs $47.5 \%$ ) ovary, identifying ovaries and follicles $>10 \mathrm{~mm}$ (55.5\% vs $31.1 \%)$. The SBM group also demonstrated more competence in terms of self-education on a cattle farm than the SNBM group (61.8\% vs 38.8\%) (35). Interesting observations have also been presented recently by French et al. (13). The hypothesis assumed that the students who in the course of practical training were assigned to the same cow all the time might be more accurate in the palpation examination in comparison to those assigned to didactic animals at random. In general, however, the experiment has demonstrated that assigning students to particular cows did not result in any improvement in the results of per rectum examinations. Conversely, it was discovered that if the time devoted to the palpation examination was limited, the factor of importance for the didactic process was selecting those cows whose behavior patterns allowed for their easy handling (13).

\section{Training on cows in a slaughterhouse}

In veterinary education, practice on cows in a slaughterhouse is commonly practiced worldwide, and used mostly in such disciplines as obstetrics (36). The main reason for that are objective difficulties. Among these, most notable are: lack of wider access to live animals in barn conditions, the necessity to maintain the well-being of cattle, large training groups, the risk of causing uterine perforation or miscarriage due to insufficient experience, as well as others $(20,26)$. At present training groups are small, consisting of about 10 students. The duration of training varies and amounts to about 30 weeks. The number of examined cows, the type of diagnosed cases and the rate of students' success at the final exam is recorded and analyzed every 3 years, and later confronted with previously defined course objectives. In addition, a questionnaire is sent to former students in order to acquire their opinion on the usefulness of the palpation training, as well as identifying the main obstacles to the educational process and collecting suggestions aimed at improving the teaching methods. The information obtained indicated that the course was useful in teaching palpation skills, even if the original objectives may have been very optimistic. A majority (96\%) of respondents expressed the opinion that the course had been very useful and applicative. A number of improvements of teaching methods were proposed, but no agreement on one suggestion was reached. Despite the fact that a large number of respondents had not used the rectal palpation in practice, only one of the surveyed defined the training as "not useful." In conclusion, it was stated that teaching the practical method of the gynecological examination by rectal palpation should be continued, and the teaching methods could be improved by introducing certain modifications (26). The fact widely discussed in the context of palpation on a live animal is that it is impossible for 
the teacher to perform a direct observation or to control the students' actions. It is also not possible to comment on the actions and correct them, which is a problem, especially at early stages of education, as beginner students often have problems with locating the anatomical structure of the generative organs, caused by the usually unknown to them structure of the rectum wall, as well as the excrements and/or air which remains there.

\section{Per rectum examination and animal well-being}

Each clinical examination may generate stress and pain for cows, which results in physiological and behavioral stress reactions (10). The duty of a person who is performing the examination should be minimizing them and not causing pain. According to the studies by Nakao et al. (30), directly after a rectal examination or after artificial insemination there is a short, yet significant growth in the level of cortisol in the blood, which lasts between 5 and 10 minutes. Such a reaction was not observed in animals on which only the vaginoscopic examination had been performed. The phenomenon was observed both among cows examined during estrus, as well as those in the luteal phase of the estrus cycle. The physiopathological value of that increase, however, remains unknown (30). In another experiment, the heart rate was monitored in the course of the per rectum examination, both among lactating (LACT) and non-lactating (NLACT) animals. An immediate pulse increase was detected among LACT cows during palpation per rectum (PPR) (an increase by 21.4 beats/ minute, on average), as well as among the NLACT cows (an increase by 20.6 beats/minute). The scale and duration of the stress reaction was larger among lactating cows than among nulligravida ones. Based on that research, the influence of PPR on stress reactions, including a cow's heart rate, may have certain impact on animal well-being on dairy farms $(23,24)$. In case of a small percentage of cows, as a result of multiple (for example, for educational purposes) or brutal examination, rectal bleeding may occur. With the well-being of the animal in mind, in such cases there is the necessity of performing the examination in the most delicate manner possible (28). One of the negative results of stress is also accumulation of radical oxygen forms. Directly after a rectal palpation, the total level of antioxidants in the plasma decreased, whereas a strong increase of nitric oxide was observed, as well as a decrease in the level of leucocytes. The values for haematocrit, on the other hand, were significantly higher in comparison to the starting values, but no notable difference was observed in the levels of red blood cells and hemoglobin concentration. Serum cholesterol levels decreased after the rectum groping, whereas the concentrations of glucose and cortisol rose significantly (the variability rates were $13.41 \%$ and $23.26 \%$, respectively). In addition, directly after palpation there was a notable increase in the total oxidant status (TOS) in the circulation in comparison to the starting values (variability rate equal to $31.78 \%)(10)$.

\section{Breed'n Betsy Training Simulation Package}

One of the older training models is a simulation package named Breed'n Betsy (7). The model was created by a veterinarian and was meant for training people who conducted artificial insemination. The model consists of a metal frame, which has a latex "hind side" of a cow, into which students can put their hands and perform a diagnosis of models of the cervix, uterus and ovaries. Breed'n Betsy allows students to constantly practice various examination methods. By means of the kit, students can use various models of the uterus to learn to diagnose pregnancy between 6 weeks and five months, artificial insemination and embryo transfer. Two holes (situated at the skull and at the spine) ensure the possibility of a student being guided by an instructor, who follows the student's hand movement. In older models, by installing real reproductive organs of a cow obtained from slaughter in the simulator's pelvis, with a rectum above it, an environment close to real-life one was ensured (14). At present, the aforementioned model is used not only by faculties of veterinary medicine of universities, but also commercial companies which offer a wide range of training in procedures that are a part of teaching cattle gynecology (www.breednbetsy.com.au). The benefits of such a teaching model based on a simulation of real-life conditions were described by Baille et al. $(4,5)$. Broader research on using the Breed'nBetsy simulation package was conducted by Bossaert et al. (9). In the first experiment, palpation skills of eight students were practiced on live animals (group A), while the skills of nine students were practiced with the use of a Breed'sBetsy simulation package (group B). The ability to locate and evaluate the structures after 25 examinations increased within the group which practiced on live animals. The group had better results and higher skills in determining the position of the uterus and evaluation of ovaries. The students who had used a simulator, on the other hand, were slightly better at pregnancy diagnosis. The research has demonstrated that using the Breed'nBetsy simulation package cannot effectively replace training on live animals. It can, however, serve as a useful additional teaching tool when combined with the classic training methods.

\section{Virtual simulators}

Recently, sophisticated models for teaching rectal palpation have been devised (2-4). Simulators such as HapticCow were created as training tools for teaching in virtual reality. They are used as a supplement to the existing training methods for the palpation examination of bovine reproductive organs in order to teach the topography of reproductive organs, pregnancy diagnosis and studying fertility $(3,21)$. Analogous devices, named HapticHorse, are also produced for horses. The simulator makes use of Haptic technology (touch feedback) and is equipped with a PHANToM haptic device (manufactured by SensAble Technologies) in its back part. It is located within a glass fiber model 
of a cow. During a training session, a student feels the computer-generated virtual objects which imitate the pelvis, ovaries, the uterus and abdomen structures. At the same time, on a computer screen the instructor follows the student's actions, controls his hand movements within the virtual cow, and provides instructions. Thus the teacher has the possibility to give commands as well as receive feedback (https://www.virtalis.com/ haptic-cow) (7). The touch simulator was also successfully used to teach the anatomy of the abdominal cavity, making it possible to locate key internal organs. Within a short time (two days), it ensured the possibility of conducting training in small groups for the total of 186 students (21). Moreover, models of early and advanced pregnancy as well as examples of pathological cases were created for the simulator, together with a teaching program. With the help of the simulator students can be trained in performing invasive procedures before attempting to study live animals. Their opinions were unanimous. All training participants agreed that the teaching method had increased their diagnostic skills. Both students and teachers appreciated the possibility of performing rectal palpation of a virtual cow which did not involve a risk of injury or a negative impact on the animal's well-being (33). In addition, it was observed that many students would return to use the simulators again. Thanks to that it was possible for them to pass their experience on to another group, thus increasing the accuracy of their examinations. It is worth adding that none of the students exceeded a 5-minute examination period, and almost $90 \%$ of students were able to distinguish the uterus and diagnose pregnancy after leaving the first classes. Another highly evaluated factor was the possibility of transmitting feedback during rectal palpation $(14,36)$. Breed'nBetsy training simulation package is used as a training supplement during anatomy and reproduction courses at the Swedish University of Agricultural Sciences (SLU) (34). Their basic goal was to evaluate the model used for teaching palpation, as well as checking to what extent it could serve as a didactic aid. In broader experiments, comparisons were made between the skills of students who had practiced the rectal examination on live animals and of those who had used a simulator. It turned out that in reference to the skill of locating ovaries and the uterus no significant differences were discovered between groups. A surprising fact, however, was that the group of volunteers who had been unassisted while using the simulator was more capable of distinguishing all structures that could be felt through the rectum in comparison to the group which was being instructed by an experienced teacher. A number of participants expressed the opinion that some parts of the model did not look realistic during a palpation examination, but the opinions on using the simulation model as such were generally positive. The obtained findings have confirmed that a virtual model may serve as a useful tool in teaching transrectal palpation (34). In another study (9), a group of students had the opportunity to participate in a training course in rectal palpation using live cows in combination with a simulation model. The students achieved much better results in in vivo palpation than students who had only trained on live cows. The authors suggest, however, that Breed'nBetsy cannot fully replace training on live animals, but can be a valuable addition to the classical teaching method.

Both Phantom Breed'n Betsy and the Haptic Cow simulator have their own advantages (Tab. 1). An interesting comparative study was conducted at the University of Veterinary Medicine in Hannover (15). Its students, during the first and the second year of their studies, have the possibility to gain basic experience in the transrectal gynecological examination of cows. The aim of the project was to grasp the influence of using a simulator on teaching an individual in comparison to theoretical preparation. Students from the first two years were assigned to two intervention groups and one control group. All of these groups were given a short, 15-minute theoretical instruction. After review of the anatomy, the control group (group A, 23 people) was given a theoretical instruction and demonstration of the palpation procedure on a bony pelvic model and two different uterine replicas. The second one (group B, 25 people) was practicing on a Breed'nBetsy simulator (BradPickford,

Tab. 1. Comparison of the differences and similarities between Breed'n Betsy phantom and virtual simulators

\begin{tabular}{|c|c|c|}
\hline Device & Breed'n Betsy Training Simulation Package & virtual simulator (e.g. HapticCow) \\
\hline Method of teaching & phantom & virtual reality \\
\hline Device characteristics & $\begin{array}{l}\text { metal frame, with a latex 'hind side' of a cow } \\
\text { equipped with various, replaceable models of } \\
\text { cervix, uterus and ovaries }\end{array}$ & $\begin{array}{l}\text { glass fiber model of a cow equipped with } \\
\text { a PHANTOM haptic device (touch feedback) }\end{array}$ \\
\hline Method of learning & palpation of the elements imitating real organs & palpation of the computer-generated virtual objects \\
\hline Students' control possibilities & two holes situated at the skull and at the spine & computerscreen \\
\hline $\begin{array}{l}\text { Evaluation of the force of finger pressing on the } \\
\text { uterus }\end{array}$ & N/A & the "Ouch-o-Meter" technology \\
\hline Device advantages & $\begin{array}{l}\text { nearly real-life environment achieved by the use of } \\
\text { real organs obtained from slaughterhouse }\end{array}$ & $\begin{array}{l}\text { teaching the anatomy of the entire abdominal } \\
\text { cavity, multitude of diagnostic task scenarios }\end{array}$ \\
\hline $\begin{array}{l}\text { Influence of the palpation examination technique } \\
\text { learning }\end{array}$ & highly useful & highly useful \\
\hline Replacement of live animal for training purposes & only partial & only partial \\
\hline
\end{tabular}


Australia), while the third one (group C, 25 people) was using a HapticCow simulator (Virtalis, Great Britain). Further examinations were conducted on live animals. The results were evaluated by a specialist with the use of a transrectal USG scan. The results of two groups who had practiced on different simulators did not vary, yet were significantly better in comparison to the control group (84\% of students made the successful examinations in group A and $80 \%$ in Cvs. $52.5 \%$ in group A). Training on a simulator allowed for more accurate distinguishing of the reproductive structures (cervix, uterus) of live animals $(15,16)$. Training on a simulator also allowed for achieving better results in comparison to the cases when only theoretical descriptions were provided. At the same time, it was discovered that the most effective teaching was conducted in groups of between 3 and 5 students (15). In the Veterinary School of the University of Glasgow students were offered two training sessions within an academic year, with feedback collected via questionnaires (7). During the first session, all students acquired basic skills by means of a standard teaching protocol. The second session was adapted to the individual needs of each student and involved simulator training of different scenarios which were likely to occur in farm conditions. In the students' opinions, the training was useful in many aspects of rectal palpation (Tab. 2 and Tab. 3). The study has also provided information which was helpful for further development of a simulator as a teaching aid (7). In order to optimize the training in pregnancy diagnosis of cows, the factors which had influence on the students' results were studied. The aim was to establish whether the training method, gender, background (farmstead, urban or mixed), earlier experience in cattle breeding and current professional interests influenced the accuracy of pregnancy diagnosis using the per rectum technique of the examination (1). Fourth-year (of a 6-year program) veterinary students (138 people assigned to six equal exposure cohorts) took one session of simulator training using a Breed'sBetsy simulation package (BB) or training on live cows (C). Next, they filled in a questionnaire concerning their gender, background and professional interests. The accuracy of their pregnancy diagnosis (state and stage of pregnancy) was evaluated after the training, in the course of which each student examined six cows whose pregnancy status had been already defined. The general accuracy of each student was defined by sensitivity and specificity (the ability to properly identify the presence or absence of pregnancy). The factors which influenced the general accuracy and higher sensitivity of the rectal examination was the training method, interest in mixed veterinary practice and issues related to breeding large animals. The students' gender and previous experience in breeding cattle were of no significant importance. Training on a BB simulator involved lower sensitivity of detecting pregnancy of cows that were less than 6-months pregnant. The sensitivity of the examination of cows which were more than 6 months pregnant was similar in the case of results obtained both after training on the BB simulator and on live cows. None of the evaluated factors was significantly related to the specificity of pregnancy diagnosis.

It is recommended to conduct didactic classes which concentrate on the specificity of pregnancy diagnosis and repeated simulator-based trainings in combination with exposition to live cows (1). One of the disadvantages of a virtual simulator was the lack of possibility to assess the force of fingers pressing the corner of the uterus, which is of special importance in detecting cow pregnancy. In 2008, a modification of Haptic Cow simulator - the „Ouch-o-Meter” - was described. The device was designed for training safe and effective pressing during per rectum palpation (1). The study by Morris et al. (29) indicated the potential of simulators while 
teaching motoric skills through seeing and touching. In the current study, the recording was made using an expert technique, which is meant to devise a measure of pressure and to create palpation profiles reflecting hand movements during an examination. Experimental studies indicate that the pressure which was considered as clinically relevant was $0.2-0.5 \mathrm{~N} / \mathrm{mm}$. The results of studies conducted by 12 veterinarians and 14 students indicate that the veterinarians were performing palpation examinations better than students. However, none of the groups was able to reliably identify more than two levels of pressure on the uterine wall out of the five-point scale, which implies that the doctors' success in clinical practice relies mostly on the evaluation of additional properties of the studied organ, such as size, shape, or texture (12).

The profession of veterinary doctor, apart from the primary goal of the patients' health, also obliges the practitioner to ensure appropriate professionalism and safety in all aspects of animal care. That also concerns animals which are used in the didactic process. Veterinarians constitute a small group at the top of professions which possess wide knowledge in animal biology. In educating students and preparing them for successful professional work, it is necessary to ensure the possibility to conduct practical experiments with animals during the academic education process. The precise character of the curriculum and the used methods which would allow for comprehensive professional preparation of future veterinary doctors is a dynamic and evolving process. In the near future, the methods used so far will be replaced by new ones, created on the basis of virtual reality. The techniques will make it possible to provide teaching without the presence of animals, with no harm to the students' best interest.

\section{References}

1. Annandale A., Annandale Ch., Fosgate G. T., Holm D. E.: Training method and other factors affecting student accuracy in bovine pregnancy diagnosis. J. Vet. Med. Educ. 2018, 45, 224-231.

2. Baillie S.: Validation of the Haptic Cow: A Simulator for training veterinary students. Ph.D. Dissertation, University of Glasgow 2007.

3. Baillie S., Crossan A., Brewster S. A., May S. A., Mellor D. J.: Evaluating an automated haptic simulator designed for veterinary students to learn bovine rectal palpation. Simul. Healthc. J. Soc. Simul. Healthc. 2010, 5, 261-266.

4. Baillie S., Crossan A., Brewster S. A., May S. A., Mellor D. J.: Preliminary development and evaluation of a bovine rectal palpation simulator for training veterinary students. Cattle Pract. 2003, 11, 101-106.

5. Baillie S., Crossan A., Brewster S., Mellor D., Reid S.: Validation of a bovine rectal palpation simulator for training veterinary students. Stud. Health Technol. Inform. 2005, 111, 33-36.

6. Baillie S., Crossan A., Forrest N., May S.: Developing the "Ouch-o-Meter" to teach safe and effective use of pressure for palpation. Proc. Haptics: Perception, Devices and Scenarios Conference, Berlin, Heidelberg 2008, 912-917.

7. Baillie S., Mellor D. J., Brewster S. A., Reid S. W. J.: Integrating a bovine rectal palpation simulator into an undergraduate veterinary curriculum. J. Vet. Med. Educ. 2005, 32, 79-85.

8. Bicalho R. C., Galvão K. N., Guard C. L., Santos J. E. P.: Optimizing the accuracy of detecting a functional corpus luteum in dairy cows. Theriogenology 2008, 70, 199-207.

9. Bossaert P., Leterme L., Caluwaerts T., Cools S., Hostens M., Kolkman I., de Kruif A.: Teaching transrectal palpation of the internal genital organs in cattle. J. Vet. Med. Educ. 2009, 36, 451-460.

10. Cingi C. C., Fatih Baser D., Karafakioglu Y. S., Fidan A. F.: Stress response in dairy cows related to rectal examination. Acta Sci. Vet. 2012, 40, 1-7.

11. Edwards M. J.: Observations on the anatomy of the reproductive organs of cows. N. Z. Vet. J. 1965, 2, 25-37.
12. Forrest N., Baillie S., Tan H. Z.: Haptic stiffness identification by veterinarians and novices: A Comparison, Proc. Third Joint Euro Haptics Conference and Symposium on Haptic Interfaces for Virtual Environment and Teleoperator Systems. Salt Lake City 2009, 1, 646-651.

13. French H. M., Dascanio J. J., Gilbert G. E., Robinson J. Q.: Bovine reproductive palpation training: Does the cow make a difference? J. Vet. Med. Educ. 2018, 45, 219-223.

14. Gandotra V. K., Ghuman S. S.: A student-centered approach to teaching anima reproduction. Adoption of Newer Reproductive Techniques in Education, Diagnostics and Research. Advanced Training Course. Department of Veterinary Gynaecology and Obstetrics College of Veterinary Science, Guru Angad Dev Veterinary and Animal Sciences University, India 2014, p. 90-96.

15. Giese H., Ehlers J. P., Gundelach Y., Geuenich K., Dilly M.: Effects of different training methods for palpation per rectum of internal genital organs on learning success and self-evaluation of students. Berl. Munch. Tierarztl. Wochenschr. 2016, 129, 216-224.

16. Giese H., Gundelach Y., Dilly M.: Simulations basiertes Training der transrektalen gynäkologischen Untersuchung beim Rind. Proc. Annual Conference of the Gesellschaft für Medizinische Ausbildung, Hamburg, Germany 2014.

17. Hanzen Ch., Pieterse M., Scenczi O., Drost M.: Relative accuracy of the identification of ovarian structures in the cow by ultrasonography and palpation per rectum. Vet. J. 2000, 159, 161-170.

18. Hart L. A., Wood M. W., Weng H. Y.: Mainstreaming alternatives in veterinary medical education: resource development and curricular reform. J. Vet. Med. Educ. 2005, 32, 473-480

19. Jaśkowski J. M.: Badanie powierzchni jajników per rectum. Lecz. Dużych Zwierząt 2006, 1, 38-42.

20. Jaśkowski J. M., Kaczmarowski M., Kulus J., Jaśkowski B. M., Herudzińska M. Gehrke M.: Rectal palpation for pregnancy check in cows - the past or an alternative to modern diagnostic methods. Med. Weter. 2019, 75, 61-67.

21. Kinnison T., Forrest N. D., Frean S. P., Baillie S.: Teaching bovine abdominal anatomy: Use of a haptic simulator. Anat. Sci. Educ. 2009, 6, 280-285.

22. Knight A.: The effectiveness of humane teaching methods in veterinary education. ALTEX 2007, 2, 91-109.

23. Kovács L., Tözsér J., Kézér F. L., Ruff F., Aubin-Wodala M., Albert E., Choukeir A., Szelényi Z., Szenci O.: Heart rate and heart rate variability in multiparous dairy cows with unassisted calvings in the periparturient period. Physiol. Behav. 2015, 139, 281-289.

24. Kovács L., Tözsér J., Szenci O., Poti P., Kézér F. L., RuffF., Gabriel-Tozser G., Hoffmann D., Bakony M., Jurkovic V.: Cardiac responses to palpation per rectum in lactating and nonlactating dairy cows. J. Dairy Sci. 2014, 97, 6955 $-6963$.

25. Leutert C., Suthar V., Heuwieser W.: Evaluation of transrectal examination of cervical diameter by palpation in dairy cows. J. Dairy Sci. 2013, 96, 1063-1070 .

26. Lopes G., Rocha A.: Teaching bovine rectal palpation with live cows in the slaughterhouse: Is it worthwhile? Reprod. Domest. Anim. 2006, 6, 510-513.

27. López-Gatius F., Camón-Urgel J.: Confirmation of estrus rates by palpation per rectum of genital organs in normal repeat dairy cows. Zntbl. VetMed. A 1991, 7, 553-556

28. Momont H.: Rectal palpation: safety issues. Proc. Dairy Herd Health Programming Conference, Minnesota 1990, 81-84.

29. Morris D., Tan H. Z., Barbagli F., Chang T., Salisbury K.: Haptic training enhances force skill learning. Proc. Second Joint EuroHaptics Conference and Symposium on Haptic Interfaces for Virtual Environment and Teleoperator Systems. Tsukaba 2007, 21-26.

30. Nakao T., Sato T., Moriyoshi M., Kawata K.: Plasma cortisol response in dairy cows to vaginoscopy, genital palpation per rectum and artificial insemination. Zentralbl. Veterinarmed A. 1994, 41, 16-21.

31. Patronek G. J., Rauch A.: Systematic review of comparative studies examining alternatives to the harmful use of animals in biomedical education. J. Am. Vet. Med. Assoc. 2007, 230, 37-43.

32. Phatak A. P., Whitmore H. L.: Greater participation by veterinarians in the reproductive management of dairy cattle. J. Am. Vet. Med. Assoc. 1991, 199, 74-76.

33. Scalese R. J., Issenberg S. B.: Effective use of simulations for the teaching and acquisition of veterinary professional and clinical skills. J. Vet. Med. Educ. $2005,4,461-467$.

34. Schaub J.: Utvärdering av rektaliseringsmodellen Breed'n Betsy. Ph.D Dissertation, Swedish University of Agricultural Sciences, Dept. of Clinical Sciences 2013

35. Simões $J .:$ Manual transrectal palpations performed by veterinary students in cows: a Surrey. REDVET Rev. Electrón. Vet. 2012, 13, 1-10.

36. Zolhavarieh S. M., Sadeghi-Nasab A., Ghanbari S., Mirshokraei P., Ruhi Athar M.: Preliminary Evaluation of Learning Performance of the Simplest Bovine Trans-rectal Palpation Phantom for Training Veterinary Students. Iranian J. Ruminant Health Res. 2016, 1, 21-30.

Corresponding author: Magdalena Herudzińska DVM, ul. Gagarina 7, 87-100 Toruń, Poland; e-mail: mherudzinska@umk.pl 